\title{
Vascular Endothelial Growth Factor (VEGF) and Prostate Pathology
}

\author{
Francisco Botelho, Francisco Pina, Pedro Silva, Gabriela Figueiredo, Francisco Cruz, Nuno \\ Lunet
}

Department of Urology, S. Joao Hospital (FB, FP, PS, FC), Department of Hygiene and Epidemiology (FB, NL), University of Porto Medical School, Department of Urology (FP, FC), University of Porto Medical School, Department of Immunology, St. John's Hospital (GF) and Institute of Public Health (NL), University of Porto, Porto, Portugal

\begin{abstract}
Purpose: Previous studies suggest that vascular endothelial growth factor (VEGF) circulating levels might improve identification of patients with prostate cancer but results are conflicting. Our aim was to compare serum VEGF levels across different prostate pathologies (including benign prostatic hyperplasia, prostatitis, high grade prostate intraepithelial neoplasia and prostate cancer) in patients at high risk of prostate cancer.

Materials and Methods: We consecutively enrolled 186 subjects with abnormal digital rectal examination and/or total PSA (tPSA) $\geq 2.5 \mathrm{ng} / \mathrm{mL}$. Blood was collected before diagnostic ultrasound guided trans-rectal prostate biopsy, or any prostate oncology treatment, to measure PSA isoforms and VEGF. Unconditional logistic regression was used to compute age-, tPSA- and free/total PSA-adjusted odds ratios (OR) and respective 95\% confidence intervals (95\% CI) for the association between serum VEGF and different prostatic pathologies.

Results: Prostate biopsy main diagnoses were normal or benign prostatic hyperplasia (27.3\%), prostatitis (16.6\%), and prostatic cancer $(55.0 \%)$. The median VEGF levels $(\mathrm{ng} / \mathrm{mL})$ in these groups were 178.2, 261.3 and $266.4(\mathrm{p}=0.029)$, respectively, but no significant differences were observed for benign vs. malignant pathologies $(215.2 \mathrm{vs} .266 .4, \mathrm{p}=0.551)$. No independent association was observed between VEGF (3rd vs. 1st third) and prostate cancer, when compared to benign conditions (adjusted OR $=1.44$; CI 95\%: 0.64-3.26).

Conclusions: In patients at high risk of prostate cancer, circulating VEGF levels have no clinical role in deciding which patients should be submitted to prostate biopsy. Prostatitis patients, often with higher PSA levels, also present high serum levels of VEGF, and their inclusion in control groups might explain the heterogeneous results in previous studies.
\end{abstract}

Key words: prostate; prostatic neoplasms; vascular endothelial growth factor $A$

Int Braz, J Urol. 2010; 36: 430-8

\section{INTRODUCTION}

Prostate cancer is the most commonly diagnosed non dermatologic malignancy and the third leading cause of cancer mortality among men in Europe (1). Prostatic specific antigen (PSA) is widely used for prostate cancer screening, despite its low accuracy across different cut-offs (2). However, the need to avoid unnecessary biopsies and missed diagnosis has led to the study of several other biomarkers that could further contribute to decide which patients should be referred for prostatic biopsy. 
Vascular Endothelial Growth Factor (VEGF) is a growth factor involved in the promotion of endothelial cell proliferation, vascular permeability and angiogenesis, which are critical stages for tumor growth and development, namely prostate cancer (3). It is synthesized by adenocarcinoma cells $(4,5)$, and in prostatic cancer patients the prostatic gland contributes considerably to circulating VEGF levels (6). Elevated plasma VEGF levels could reflect prostatic VEGF production, making VEGF a potentially interesting tumor marker to support the decision of submitting a patient to prostatic biopsy.

Previous studies on this topic are conflicting. Some authors have found higher levels of VEGF in prostatic cancer patients (7-10), while others found no differences between subjects with benign prostatic hyperplasia (BPH) and those with malignant disease $(11,12)$, or increased values only in patients with metastatic prostatic cancer (13) or hormonerefractory disease (14). However, most previous studies evaluated relatively small samples $(8,9,11$ 14) and all suffered from limited-challenge bias, as prostatitis, which may interfere with the diagnostic value of VEGF, was not evaluated separately in any of the studies and in many studies the control group only included subjects with no suspicion of prostatic cancer $(7,10,13)$.

We attempted to evaluate VEGF as a diagnostic tool for prostatic cancer, comparing its serum levels across groups of patients with suspected prostate cancer, presenting different prostatic pathologies (including BPH, prostatitis, high grade prostate intraepithelial neoplasia (HGPIN) and prostate cancer).

\section{MATERIALS AND METHODS}

\section{Patient Selection}

During 2006 we consecutively enrolled 186 candidates referred to ultrasound guided trans-rectal prostate biopsy, on the basis of abnormal rectal examination and/or elevated total PSA (tPSA) levels ( $\geq$ $2.5 \mathrm{ng} / \mathrm{mL}$ ), in the Department of Urology of S. Joao Hospital. None of the patients received hormonal therapy, radiotherapy or chemotherapy before undergoing prostate biopsy.

\section{Measurement of Biomarkers}

Blood was collected from all participants prior to biopsy, and samples were allowed to clot for 30 minutes before centrifugation. Part of the serum was used for a new assessment of tPSA, free PSA (fPSA) and complexed PSA (cPSA). The remaining serum was frozen $\left(-20^{\circ} \mathrm{C}\right)$, and subsequently was used for VEGF quantification by ELISA (quantitative sandwich enzyme immunoassay technique) double determinations with Quantikine ${ }^{\circledR}$, a Human VEGF Immunoassay (R\&D Systems, Minneapolis, MN).

\section{Outcome Evaluation}

The final prostate pathology and the prostate cancer cases Gleason score were defined by biopsy results. The number of biopsy cores ranged from 8 to 13. All prostatic biopsies were reviewed by two different pathologists that were blinded to the patients' different PSA isoforms and VEGF values. Patients were grouped into four mutually-exclusive groups, according to the most severe diagnosis observed in the biopsy specimens, as follows (ordered by increasing severity): normal prostate or $\mathrm{BPH}$ (N/BPH), prostatitis, HGPIN, and prostatic cancer.

\section{Statistical Analysis}

The Kruskal-Wallis test was used to compare quantitative variables across prostate pathology groups. Spearman correlation coefficients were computed to quantify the association between VEGF and age, tPSA, cPSA and f/t PSA ratio.

A receiver operating characteristic (ROC) analysis was used to compute the area under the ROC curve (AUC) and to identify the VEGF level cut-off for which a higher proportion of patients was correctly classified when distinguishing prostatic cancer from benign diagnosis.

Unconditional logistic regression was used to compute odds ratios (OR) and respective $95 \%$ confidence intervals $(95 \% \mathrm{CI})$ for the association between serum VEGF levels (groups defined using tertiles as cut-offs and the cut-off defined by the ROC 
curve analysis) and different prostatic pathologies, crude and adjusted for age, tPSA and f/tPSA. The tPSA levels were modeled after log-transformation. Further analyses were conducted combining N/BPH, prostatitis and HGPIN in a group of benign pathology. Due to the low number of patients with HGPIN, these patients were excluded from the analyses by prostatic pathology subgroups, and considered only when comparing malign with all types of benign pathology.

Statistically significance in this study was set as $\mathrm{p}<0.05$. All reported $\mathrm{p}$ values are two-sided.
Statistical analysis was performed using STATA ${ }^{\circledR}$, version 9.2.

\section{RESULTS}

The median age of the participants was 68 years (percentile 25-percentile 75 [P25-P75]: range 62-73), the median tPSA level was $7.4 \mathrm{ng} / \mathrm{mL}$ (P25P75: 5.4-12.1) and the median $\mathrm{f} / \mathrm{tPSA}$ ratio was 0.16 (P25-P75: 0.08-0.23).

Table 1 - Characteristics of the participants stratified by prostatic histology.

\begin{tabular}{|c|c|c|c|c|c|c|}
\hline & & N / BPH & Prostatitis & HGPIN & Prostate Cancer & p Value \\
\hline \multicolumn{2}{|c|}{$\mathrm{N}$} & 51 & 30 & 6 & 99 & \\
\hline \multicolumn{2}{|c|}{ Median Age (years) } & 67.0 & 67.0 & 67.0 & 69.0 & 0.678 \\
\hline \multirow{3}{*}{$\begin{array}{l}\text { Age } \\
\text { (years) }\end{array}$} & $\leq 60$ & $13(25.5 \%)$ & $5(16.7 \%)$ & $1(16.7 \%)$ & $16(16.2 \%)$ & 0.766 \\
\hline & $60-70$ & $20(39.2 \%)$ & $15(50.0 \%)$ & $3(50.0 \%)$ & $40(40.4 \%)$ & \\
\hline & $>70$ & $18(35.3 \%)$ & $10(33.3 \%)$ & $2(33.3 \%)$ & $43(43.4 \%)$ & \\
\hline \multicolumn{2}{|c|}{ Median tPSA $(\mathrm{ng} / \mathrm{mL})$} & 5.7 & 9.9 & 6.1 & 8.3 & $<0.001$ \\
\hline \multirow{3}{*}{$\begin{array}{l}\text { tPSA } \\
(\mathrm{ng} / \mathrm{mL})\end{array}$} & $\leq 4$ & $11(22.0 \%)$ & $1(3.4 \%)$ & $1(16.7 \%)$ & $10(10.1 \%)$ & 0.006 \\
\hline & $4-10$ & $33(66.0 \%)$ & $14(48.3 \%)$ & $4(66.7 \%)$ & $51(51.5 \%)$ & \\
\hline & $>10$ & $6(12.0 \%)$ & $14(48.3 \%)$ & $1(16.7 \%)$ & $38(38.4 \%)$ & \\
\hline \multicolumn{2}{|c|}{ Median cPSA $(\mathrm{ng} / \mathrm{mL})$} & 4.0 & 6.7 & 4.6 & 6.4 & $<0.001$ \\
\hline \multirow{3}{*}{$\begin{array}{l}\text { cPSA } \\
(\mathrm{ng} / \mathrm{mL})\end{array}$} & $\leq 4$ & $26(51.0 \%)$ & $5(1.2 \%)$ & $3(50.0 \%)$ & $18(18.6 \%)$ & $<0.001$ \\
\hline & $4-10$ & $24(47.1 \%)$ & $21(72.4 \%)$ & $3(50.0 \%)$ & $53(54.6 \%)$ & \\
\hline & $>10$ & $1(2.0 \%)$ & $3(10.3 \%)$ & $0(0.0 \%)$ & $26(26.8 \%)$ & \\
\hline \multicolumn{2}{|c|}{ Median f/tPSA ratio } & 0.22 & 0.20 & 0.22 & 0.11 & $<0.001$ \\
\hline \multirow[t]{2}{*}{ f/tPSA ratio } & $\leq 0.15$ & $14(28.0 \%)$ & $10(34.5 \%)$ & $0(0.0 \%)$ & $68(68.7 \%)$ & $<0.001$ \\
\hline & $>0.15$ & $36(72.0 \%)$ & $19(65.5 \%)$ & $6(100.0 \%)$ & $31(31.3 \%)$ & \\
\hline \multicolumn{2}{|c|}{ Median VEGF $(\mathrm{pg} / \mathrm{mL})$} & 178.2 & 261.3 & 251.9 & 266.4 & 0.067 \\
\hline \multirow{3}{*}{$\begin{array}{l}\text { VEGF* } \\
(\mathrm{pg} / \mathrm{mL})\end{array}$} & $\leq 170$ & $24(47.1 \%)$ & $6(20.0 \%)$ & $2(33.3 \%)$ & $31(31.3 \%)$ & 0.087 \\
\hline & $171-335$ & $18(35.3 \%)$ & $11(36.7 \%)$ & $3(50.0 \%)$ & $31(31.3 \%)$ & \\
\hline & $>335$ & $9(17.6 \%)$ & $14(43.3 \%)$ & $1(16.7 \%)$ & $37(37.4 \%)$ & \\
\hline
\end{tabular}

* Tertiles were used to define cut-offs. $N$ / BPH = normal prostate or benign prostate hyperplasia; HGPIN = high grade prostate intraepithelial neoplasia; PSA: prostate-specific antigen; VEGF = vascular endothelial growth factor 
Prostatic biopsies revealed prostatic cancer in 99 cases $(53.2 \%)$, prostatitis in 30 cases $(16.1 \%)$, HGPIN in 6 cases (3.2\%), BPH in 32 cases $(17.2 \%)$ and normal prostate in the remaining 19 participants (10.2\%). Among prostatic cancer cases the Gleason score was 6 in $21.4 \%$ patients, 7 in $51.1 \%$ and 8 or higher in $23.4 \%$.

Table-1 summarizes participants' characteristics stratified by prostatic histology. Age was similar between groups, but tPSA and cPSA were significantly higher in patients with prostatitis $(9.9$ and $6.7 \mathrm{ng} / \mathrm{mL}$, respectively) and prostatic cancer ( 8.3 and $6.4 \mathrm{ng} / \mathrm{mL}$ respectively) when compared to N/BPH (5.7 and 4.0 $\mathrm{ng} / \mathrm{mL}$, respectively). The median $\mathrm{f} / \mathrm{t}$ PSA ratio was lower in prostatic cancer patients compared to patients with benign histology ( 0.11 vs. 0.21$)$.

The median serum VEGF level in our sample was $232.3 \mathrm{pg} / \mathrm{mL}$ (range: 16.4-1648.3 g/mL; P25-P75: $144.0-339.6 \mathrm{pg} / \mathrm{mL})$. There was a weak positive correlation between VEGF and IPSA $(r=0.18 ; p=0.013)$ and a weak negative correlation between VEGF and $\mathrm{f} / \mathrm{t}$ PSA ratio $(\mathrm{r}=-0.17 ; \mathrm{p}=0.017)$. No significant association was observed with age $(r=-0.04 ; p=0.56)$ or cPSA $(r=0.15 ; p=0.054)$. These results were similar when stratified by prostatic pathology (data not shown).
As presented in Figure-1, VEGF levels were significantly higher in prostatic cancer and prostatitis than in N/BPH (median: 266.4, 261.3 and 178.2 $\mathrm{pg} / \mathrm{mL}$, respectively; $\mathrm{p}=0.029)$, but no statistically significant difference was observed when comparing prostatic cancer with benign pathology (median: 215.2 vs. $266.4 \mathrm{pg} / \mathrm{mL}$, respectively; $\mathrm{p}=0.551$ ). The median VEGF levels were similar when the analysis was restricted to patients with tPSA between 2.5 and 10 $\mathrm{ng} / \mathrm{mL}(211.5 \mathrm{pg} / \mathrm{mL}$ for benign histology and 246.7 $\mathrm{pg} / \mathrm{mL}$ for prostatic cancer; $\mathrm{p}=0.67$ ). These results were similar if patients with HGPIN were excluded (data not shown).

The ROC curve of VEGF serum levels for the detection of prostatic malignancy is presented in Figure-2. The AUC was 0.53 (95\% CI: 0.44-0.61) and the cut-off value for which a higher proportion of patients was correctly classified (57.0\%) was 266.4 $\mathrm{pg} / \mathrm{mL}$.

Higher VEGF levels (3rd third vs. 1st third) were approximately twice more likely in patients with prostate cancer compared to N/BPH, but the adjusted estimates were not significantly different from unity $(\mathrm{OR}=2.19,95 \%$ CI: 0.76-6.31) (Table-2).

Results comparing benign and malignant prostatic pathology are presented in Table-3. In gen-

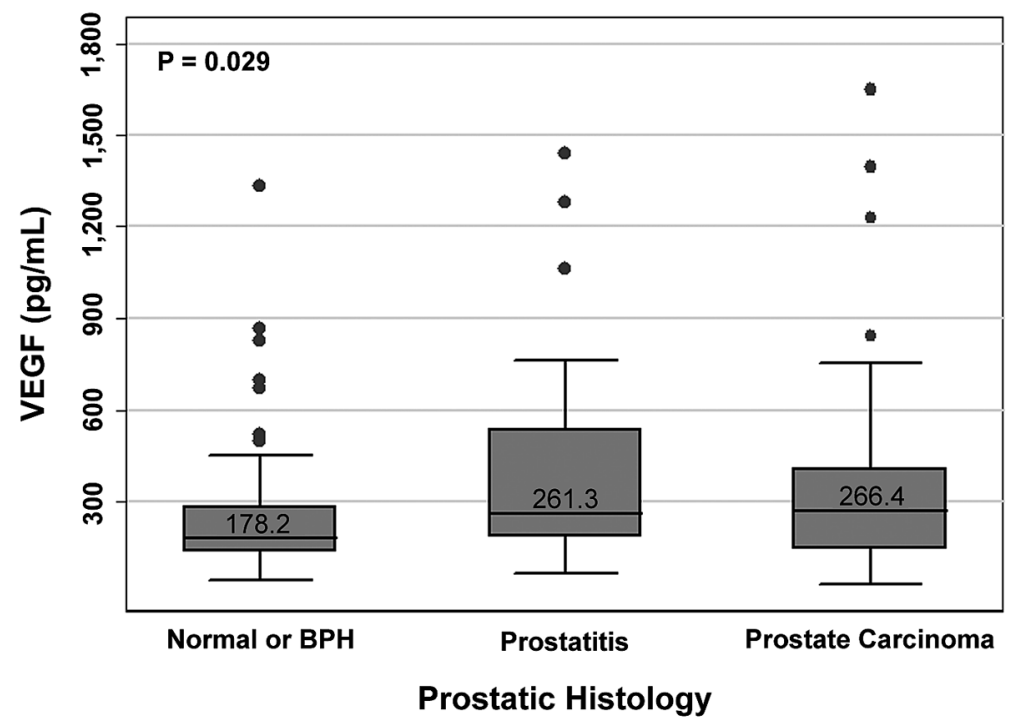

Figure 1 - Serum levels of vascular endothelial growth factor (VEGF), according to prostate biopsy histology. BPH: benign prostatic hyperplasia. 


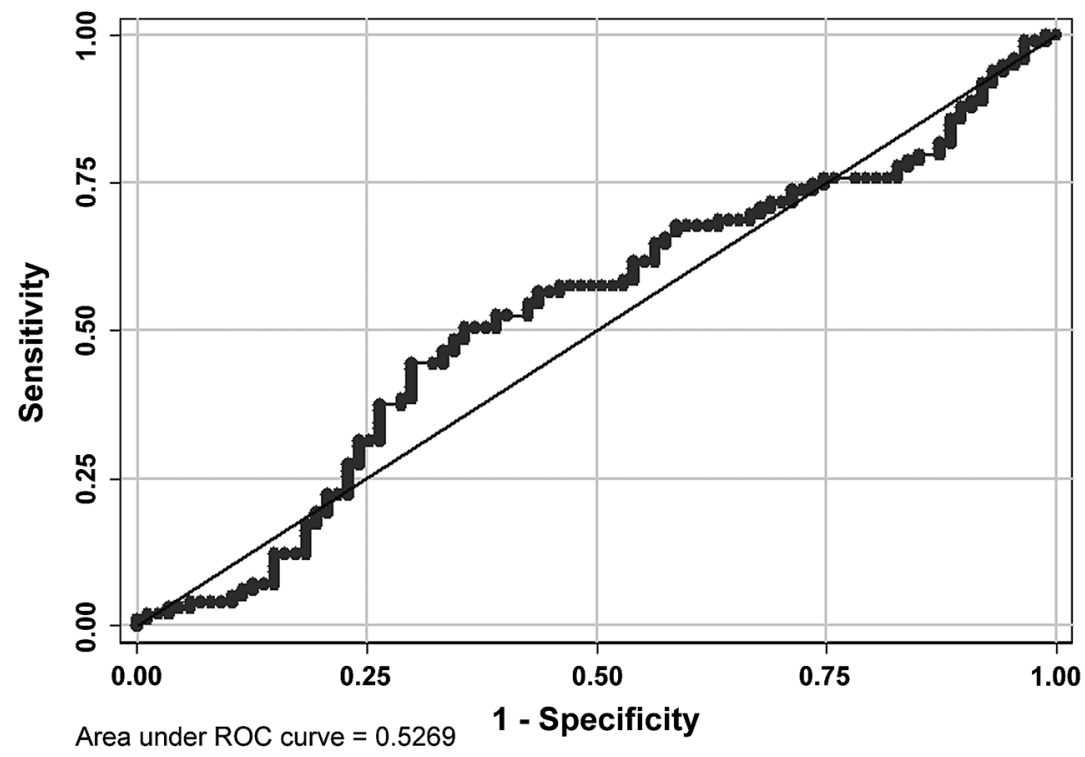

Figure 2 - Receiver operating characteristic (ROC) curves for vascular endothelial growth factor (VEGF) serum levels as a test for diagnosis prostate carcinoma using the biopsy results as the gold standard.

eral, OR estimates were lower than when N/BPH was used as reference. The age- and PSA-adjusted OR for the association between prostatic cancer and higher VEGF levels (3rd third vs. 1st third) was 1.44 (95\% CI: 0.64-3.26).
In prostatic cancer patients, the VEGF levels were not significantly different across Gleason score groups. The median values were $258.8 \mathrm{pg} / \mathrm{mL}$ for patients with histological Gleason score 6, were 272.5 $\mathrm{pg} / \mathrm{mL}$ for those with Gleason score 7 and $234.8 \mathrm{pg} /$

Table 2-Multivariate logistic analysis of the association between vascular endothelial growth factor (VEGF) and prostate histology.

\begin{tabular}{cccccccc}
\hline & N / BPH & \multicolumn{3}{c}{ Prostatitis } & \multicolumn{3}{c}{ Prostate Cancer } \\
$\begin{array}{c}\text { Serum VEGF } \\
(\mathrm{pg} / \mathrm{mL})\end{array}$ & $\begin{array}{c}\mathbf{N} \\
(\%)\end{array}$ & $\begin{array}{c}\mathbf{N} \\
(\%)\end{array}$ & $\begin{array}{c}\text { OR } \\
(95 \% \mathrm{CI})\end{array}$ & $\begin{array}{c}\mathbf{O R}^{*} \\
(95 \% \mathrm{CI})\end{array}$ & $\begin{array}{c}\mathbf{N} \\
(\%)\end{array}$ & $\begin{array}{c}\text { OR } \\
(95 \% \mathrm{CI})\end{array}$ & $\begin{array}{c}\text { OR }^{*} \\
(95 \% \mathrm{CI})\end{array}$ \\
\hline$<266.4^{\S}$ & $37(72.6)$ & 16 & 1 & 1 & 50 & 1 (reference) & 1 \\
& & $(53.3)$ & $($ reference) & $($ reference) & $(50.5)$ & & $($ reference) \\
$>266.4^{\S}$ & $14(27.4)$ & 14 & 2.31 & 1.63 & 49 & $2.59(1.25-$ & 1.89 \\
& & $(46.7)$ & $(0.90-5.95)$ & $(0.53-5.03)$ & $(49.5)$ & $5.38)$ & $(0.81-4.38)$ \\
$\leq 170^{\dagger}$ & $24(47.1)$ & 6 & 1 & 1 & 31 & 1 & 1 \\
& & $(19.4)$ & $($ reference) & $($ reference) & $(31.3)$ & $($ reference) & $($ reference) \\
$171-335^{\dagger}$ & $18(35.3)$ & 11 & 5.78 & 4.57 & 31 & 3.18 & 2.18 \\
& & $(35.5)$ & $(1.68-19.85)$ & $(1.00-20.94)$ & $(31.3)$ & $(1.29-7.85)$ & $(0.79-6.05)$ \\
$>335^{\dagger}$ & $9(17.6)$ & 14 & 2.36 & 1.05 & 37 & 2.39 & 2.19 \\
& & $(45.2)$ & $(0.76-7.34)$ & $(0.28-3.99)$ & $(37.4)$ & $(0.94-6.06)$ & $(0.76-6.31)$ \\
\hline
\end{tabular}

$*=$ adjusted for age; $t P S A$ and f/tPSA; $\S=$ cut-off that optimizes proportion of patients correctly classified; $\uparrow=$ tertiles were used to define cut-offs; $N / B P H=$ normal prostate or benign prostate hyperplasia. 
Table 3 - Multivariate logistic analysis of the association of vascular endothelial growth factor (VEGF) with prostate cancer.

\begin{tabular}{ccccc}
\hline & Benign Histology & \multicolumn{3}{c}{ Prostate Cancer } \\
Serum VEGF $(\mathbf{p g} / \mathbf{m L})$ & $\mathbf{N}(\%)$ & $\mathbf{N}(\%)$ & OR $(95 \% \mathrm{CI})$ & OR* $^{*}(95 \% \mathrm{CI})$ \\
\hline$<266.4^{\S}$ & $56(64.4)$ & $50(50.5)$ & 1 (reference) & 1 (reference) \\
$>266.4^{\S}$ & $31(35.6)$ & $49(49.5)$ & $1.77(0.98-3.19)$ & $1.22(0.62-2.40)$ \\
$\leq 170^{\dagger}$ & $32(36.8)$ & $31(31.3)$ & 1 (reference) & 1 (reference) \\
$171-335^{\dagger}$ & $32(36.8)$ & $31(31.3)$ & $1.66(0.81-3.40)$ & $1.01(0.44-2.31)$ \\
$>335^{\dagger}$ & $23(26.4)$ & $37(37.4)$ & $1.66(0.81-3.40)$ & $1.44(0.64-3.26)$ \\
\hline
\end{tabular}

$*=$ adjusted for age, tPSA and f/tPSA; $\xi=$ cut-off that optimizes proportion of patients correctly classified; $\%=$ tertiles were used to define cut-offs; benign histology = including normal prostate or benign prostate hyperplasia, prostatitis and high grade prostate intraepithelial neoplasia; $C I=$ confidence intervals; OR: odds ratio.

$\mathrm{mL}$ for those with the more aggressive score Gleason score $8-10(p=0.716)$.

\section{COMMENTS}

VEGF levels are higher in subjects with prostatitis and prostatic cancer compared to patients at high prostate cancer risk but whose prostatic biopsy only revealed normal or hyperplasic tissue. However, in this consecutive series of patients eligible for prostatic biopsy there were no overall differences in VEGF serum levels between subjects with benign prostatic disease and prostate cancer cases.

Our results contribute to explain the heterogeneity observed in the literature on this topic. Prostatitis is an inflammatory condition associated with angiogenesis that raises VEGF levels, similar to the observed in prostate cancer, and may be highly prevalent in patients with increased tPSA levels. Reports of prostatitis prevalence range from $10 \%$ to $63 \%$ (15), and was $16.1 \%$ in our series. We observed no relevant difference in VEGF circulating levels between patients with benign prostatic histology and cancer, when patients with prostatitis were also considered in the latter group. The two previous studies $(11,12)$ that evaluated participants with high risk of prostate cancer also observed no significant associations between cancer and VEGF levels.

Other studies $(7-10,13,14)$ showed higher VEGF levels in patients with prostate cancer when compared with healthy controls or subjects with benign prostatic hypertrophy. Such comparisons however, are not clinically relevant since elevated tPSA is the most frequent indication for prostatic biopsy, and reflect limited-challenge-bias $(16,17)$. A diagnostic test must be evaluated in a clinically relevant population, preferably in a consecutive series of individuals in whom the target condition is suspected (17). Studies using healthy controls, not representing the whole spectrum of potential diagnosis alternative to prostate cancer which are able to generate false-positive results, namely when prostatitis is present, produce inflated estimates of diagnostic accuracy (18).

Also, in some of these studies $(7,10,13,14)$ whose controls were not suspected of having prostate cancer, the investigators did not perform any biopsy in the individuals that were categorized as healthy or only presenting BPH based on low PSA levels and a negative digital rectal examination. However, Thompson et al. (19) detected prostatic cancer in 10.1 percent among those with values of 0.6 to 1.0 $\mathrm{ng} / \mathrm{mL}, 17.0$ percent among those with values of 1.1 to $2.0 \mathrm{ng} / \mathrm{mL}, 23.9$ percent among those with values of 2.1 to $3.0 \mathrm{n} / \mathrm{mL}$, and 26.9 percent among those with values of 3.1 to $4.0 \mathrm{ng} / \mathrm{mL}$. These values can lead to a differential information bias that would cause an underestimation of the true association measure.

VEGF could also be important in clinical practice if its levels were higher in patients with worst prognosis prostatic cancer (those with higher Gleason score or in higher clinical stage). In our study, 
we did not find any significant associations between VEGF levels and Gleason score in the 99 prostate cancer patients, in accordance with previous reports $(8,11,20,21)$. Only Shariat et al. (7) describe higher VEGF levels in those with higher Gleason score, and Duque et al. (13) report higher levels in patients with Gleason score $\geq 8$ although no positive relation between Gleason score and plasma VEGF was observed. Differences in VEGF levels between metastatic and localized prostatic cancer have been reported (13), but we decided not to make this type of evaluation in our study due to the restricted number of cases.

To measure serum VEGF we used the kit from R\&D Systems that has an intra-assay coefficient of variation of $4.5 \%$ (22). The Elisa kit has been used previously $(7,12,13)$ and is considered adequate to measure VEGF in serum or plasma.

Circulating VEGF in serum from cancer patients may reflect an aggregate of tumor-cell and platelet-stored VEGF (23). To better reflect the disease-related circulating VEGF levels, the use of rapidly processing citrated plasma samples and additional centrifugation has been recommended (23). This has been disputed, by other authors, suggesting that both plasma and serum levels of VEGF may be equally useful (24). Nonetheless, there is a potential for an information bias in our VEGF levels that we cannot exclude, although its effects are difficult to predict.

The use of circulating VEGF to predict disease staging, patient outcome, early identifying patients at higher risk of lymph node metastases or selecting patients for early systemic intervention or adjuvant radiation therapy, sparing others from the associated morbidity with these treatment options, are still under study and can provide important advances in prostate oncology. Ultimately, a better understanding of the VEGF system should provide additional knowledge about prostatic cancer growth that would allow us to develop better molecular markers for use in clinical practice.

Our results show that VEGF levels have no clinical importance in deciding which patients suspected of having prostatic cancer should be submitted to prostatic biopsy. The exclusion of patients with prostatitis from the control group is the probable cause of the heterogeneous results in previous studies.

\section{CONFLICT OF INTEREST}

None declared.

\section{REFERENCES}

1. Ferlay J, Autier P, Boniol M, Heanue M, Colombet M, Boyle P: Estimates of the cancer incidence and mortality in Europe in 2006. Ann Oncol. 2007; 18: 581-92.

2. Brawer MK: Prostate-specific antigen. Semin Surg Oncol. 2000; 18: 3-9.

3. Benjamin LE, Golijanin D, Itin A, Pode D, Keshet E: Selective ablation of immature blood vessels in established human tumors follows vascular endothelial growth factor withdrawal. J Clin Invest. 1999; 103: 159-65.

4. Ferrer FA, Miller LJ, Andrawis RI, Kurtzman SH, Albertsen PC, Laudone VP, et al.: Angiogenesis and prostate cancer: in vivo and in vitro expression of angiogenesis factors by prostate cancer cells. Urology. 1998; 51: 161-7.

5. Stefanou D, Batistatou A, Kamina S, Arkoumani E, Papachristou DJ, Agnantis NJ: Expression of vascular endothelial growth factor (VEGF) and association with microvessel density in benign prostatic hyperplasia and prostate cancer. In Vivo. 2004; 18: 155-60.

6. George DJ, Regan MM, Oh WK, Tay MH, Manola J, Decalo N, et al.: Radical prostatectomy lowers plasma vascular endothelial growth factor levels in patients with prostate cancer. Urology. 2004; 63: 327-32.

7. Shariat SF, Anwuri VA, Lamb DJ, Shah NV, Wheeler TM, Slawin KM: Association of preoperative plasma levels of vascular endothelial growth factor and soluble vascular cell adhesion molecule-1 with lymph node status and biochemical progression after radical prostatectomy. J Clin Oncol. 2004; 22: 1655-63.

8. Trapeznikova MF, Shibaev AN, Kazantseva IA, Mironova OS, Gurevich LE, Morozov AP, et al.: Vascular endothelial growth factor in patients with prostate cancer and benign prostatic hyperplasia. Vestn Ross Akad Med Nauk. 2005; 5: 14-6.

9. Trapeznikova MF, Shibaeva AN, Ianshin AA, Urenkov SB, Mironova OS, Kazantseva IA, et al.: Vascular endothelial growth factor and insulin-like-growth factors in prostate cancer. Urologiia. 2004; 1: 17-21.

10. Caine GJ, Lip GY, Stonelake PS, Ryan P, Blann AD: Platelet activation, coagulation and angiogenesis in 
breast and prostate carcinoma. Thromb Haemost. 2004; 92: 185-90.

11. Peyromaure M, Goulvestre C, Fulla Y, Grabar S, Debré B, Dinh-Xuan AT: Serum levels of vascular endothelial growth factor in patients undergoing prostate biopsy for suspicion of prostate cancer. Urology. 2005; 66: 687-91.

12. Walsh K, Sherwood RA, Dew TK, Mulvin D: Angiogenic peptides in prostatic disease. BJU Int. 1999; 84: 1081-3.

13. Duque JL, Loughlin KR, Adam RM, Kantoff PW, Zurakowski D, Freeman MR: Plasma levels of vascular endothelial growth factor are increased in patients with metastatic prostate cancer. Urology. 1999; 54: 523-7.

14. Jones A, Fujiyama C, Turner K, Fuggle S, Cranston D, Bicknell R, et al.: Elevated serum vascular endothelial growth factor in patients with hormone-escaped prostate cancer. BJU Int. 2000; 85: 276-80.

15. Hochreiter WW: The issue of prostate cancer evaluation in men with elevated prostate-specific antigen and chronic prostatitis. Andrologia. 2008; 40: 130-3.

16. Rutjes AW, Reitsma JB, Di Nisio M, Smidt N, van Rijn JC, Bossuyt PM: Evidence of bias and variation in diagnostic accuracy studies. CMAJ. 2006; 174: 469-76.

17. Rutjes AW, Reitsma JB, Vandenbroucke JP, Glas AS, Bossuyt PM: Case-control and two-gate designs in diagnostic accuracy studies. Clin Chem. 2005; 51: 1335-41.

18. Lijmer JG, Mol BW, Heisterkamp S, Bonsel GJ, Prins $\mathrm{MH}$, van der Meulen JH, et al.: Empirical evidence of design-related bias in studies of diagnostic tests.
JAMA. 1999; 282: 1061-6. Erratum in: JAMA. 2000; 283: 1963.

19. Thompson IM, Pauler DK, Goodman PJ, Tangen CM, Lucia MS, Parnes HL, et al.: Prevalence of prostate cancer among men with a prostate-specific antigen level < or $=4.0 \mathrm{ng}$ per milliliter. N Engl J Med. 2004; 350: 2239-46. Erratum in: N Engl J Med. 2004; 351: 1470 .

20. Li H, Kantoff PW, Ma J, Stampfer MJ, George DJ: Prediagnostic plasma vascular endothelial growth factor levels and risk of prostate cancer. Cancer Epidemiol Biomarkers Prev. 2005; 14: 1557-61.

21. Peyromaure M, Badoual C, Camparo P, Grabar S, Goulvestre C, Fulla Y, et al.: Plasma levels and expression of vascular endothelial growth factor-A in human localized prostate cancer. Oncol Rep. 2007; 18: $145-9$.

22. Human VEGF ELISA Kit, Quantikine SixPak from R\&D Systems. R\&D Systems; [cited April 2009]; Available at: http:/www.biocompare.com/ProductDetails/210083/Human-VEGF-ELISA-Kit,-QuantikineSixPak.html

23. Banks RE, Forbes MA, Kinsey SE, Stanley A, Ingham $\mathrm{E}$, Walters $\mathrm{C}$, et al.: Release of the angiogenic cytokine vascular endothelial growth factor (VEGF) from platelets: significance for VEGF measurements and cancer biology. Br J Cancer. 1998; 77: 956-64.

24. Bachelot T, Ray-Coquard I, Menetrier-Caux C, Rastkha M, Duc A, Blay JY: Prognostic value of serum levels of interleukin 6 and of serum and plasma levels of vascular endothelial growth factor in hormone-refractory metastatic breast cancer patients. Br J Cancer. 2003; 88: 1721-6.
Accepted after revision: December 8, 2009

\section{Correspondence address:}

Dr. Francisco Botelho

Serviço de Higiene e Epidemiologia

Faculdade de Medicina da Universidade do Porto

Alameda Prof. Hernâni Monteiro

Porto, 4200-319, Portugal

Fax: + 3512 2509-5618

E-mail: francisco.botelho@gmail.com 


\section{EDITORIAL COMMENT}

Neovascularization is required to sustain growth of solid tumors and the main proteins involved in the angiogenic cascade are fibroblast growth factor (bFGF), vascular endothelial growth factor (VEGF) and platelet-derived growth factor (PDGF). The possibility to detect VEGF in urine post prostate massage or in serum of men in risk to develop the neoplasia is tempting and could help the lack of specificity of prostate specific antigen (PSA), avoiding unnecessary biopsies. VEGF has already been described as an important player in prostate carcinogenesis, allowing tumor growth and dissemination. The authors studied VEGF in serum of patients with abnormalities on digital rectal examination and/ or PSA $\geq 2.5 \mathrm{ng} / \mathrm{mL}$ showing higher levels of VEGF in cancer but also in prostatitis. Prostatitis has been related to cancer development by some authors, and Narayan et al. (1) have recently described prostate cancer induction in animal models using testosterone and $\mathrm{N}$-methyl-N-nitrosourea showing abnormal expression of inflammatory mediators and VEGF. VEGF serum levels may also be elevated in patients with prostatitis in the present study should be interpreted as a link between chronic inflammation and the development of the neoplasia. VEGF expression should be an important player for tumor initiation and/or progression related to chronic inflammation. Even though the authors concluded that VEGF serum detection is not helpful to indicate prostate biopsy, their results should be used as a new trail to be explored in prostate carcinogenesis, opening a new possibility of using angiogenesis inhibitors as prostate cancer prevention.

\section{REFERENCE}

1. Narayanan NK, Nargi D, Horton L, Reddy BS, Bosland MC, Narayanan BA: Inflammatory processes of prostate tissue microenvironment drive rat prostate carcinogenesis: preventive effects of celecoxib. Prostate. 2009; 69: 133-41.

Dr. Katia Ramos Moreira Leite Laboratory for Medical Investigation, LIM55 University of Sao Paulo Medical School Sao Paulo, SP, Brazil E-mail:katiaramos@uol.com.br 